\title{
Recency judgments in a short-term memory task'
}

\author{
JOHN BRELSFORD, JR., RICHARD FREUND AND DEWEY RUNDUS
}

STANFORD UNIVERSITY

On each trial of a short-term memory task, Ss were required to give the correct response to a paired-associate stimulus and to estimate the number of trials intervening between study and test on that stimulus. On trials where an incorrect paired-associate response was made, judgment of the number of intervening items was relatively independent of the actual number of intervening items. On trials where a correct pairedassociate response was made, judgment of the number of intervening items was accurate for recent items but incorrect for more distant items.

In studies involving short-term memory for pairedassociates it has typically been found that the probability of a correct response to a particular stimulus decreases as a function of the number of stimulus-response pairs intervening between study and test on the given stimulus. It seems reasonable to suppose that, in addition to giving the paired-associate response to a particular stimulus, Ss should also be able to make recency judgments (i.e., report the number of items that intervene between study and test on a specific stimulus). Both Yntema \& Trask (1963) and Peterson (1966) have found that there is a positive correlation between estimates of recency and the actual number of items intervening between study and test on a specific stimulus.

It may be of interest to determine whether the information that an Shas about recency is related to other information he has about the stimulus. Specifically, what is the relationship between an S's ability to judge the number of intervening items and his ability to give the correct paired-associate response for a given stimulus? The present study is an attempt to investigate recency judgments as a joint function of the number of items intervening between study and test and the type of pairedassociate response (i.e., correct or incorrect) given to the stimulus in question.

Subjects

The Ss were eight students from Stanford University. Each $\mathrm{S}$ participated in 10 1/2-h experimental sessions and was paid 2 dollars for each session.

\section{Apparafus}

Programming, stimulus generation, and response recording were carried out with an on-line PDP-1 computer. Stimuli were electronically generated and displayed on the face of a cathode ray tube (CRT). Responses were made on an electric typewriter keyboard located immediately below the lower edge of the CRT. Stimuli and responses

The stimuli were pronounceable CVC trigrams of low association value. The responses were the 26 letters of the English alphabet.

Procedure

The procedure was similar to that used by Atkinson,
Brelsford, \& Shiffrin (1967). Each session began with a series of eight consecutive study trials. On each study trial the word "study" appeared on the upper face of the CRT. Beneath "study" there appeared one of the stimuli to be used in the session along with a randomlyselected response member. Ss had been initially instructed to say aloud, and to try to remember the association between, the stimulus-response pairs which appeared along with "study." The duration of each study trial was $2 \mathrm{sec}$. Following these eight initial study trials the session proper began.

Each trial consisted of the following series of events. (1) The word "test" appeared on the upper face of the CRT. Beneath "test" there appeared a stimulus that had been randomly selected from the eight stimuli. Ss had been instructed that, when "test" and a stimulus appeared on the CRT, they were to respond by pressing the key corresponding to the letter of the alphabet which had been associated with that stimulus when it was presented for study. The test portion of each trial lasted for $2 \mathrm{sec}$, followed by a 1-8ec period in which the CRT was blank. (2) The words "judge lag" appeared on the upper face of the CRT and remained there for $2 \mathrm{sec}$. Ss had been instructed that, while this message appeared on the screen, they were to judge "how far back" in the succession of trials the tested stimulus had appeared for study and to respond by pressing the appropriate key. Keys numbered from 1 to 13 and "14 or more" were available for the lag judgment. Following the lag judgment the CRT was blank for $1 / 2$ sec.(3) Feedback about the paired-associate response to the tested item was given by the appearance of "correct" or "wrong" on the upper face of the CRT. The duration of the feedback message was $1 / 2 \mathrm{sec}$, and it was followed by a blank CRT for $1 / 2 \mathrm{sec}$. (4) The word "study" appeared on the upper face of the CRT, below which a new stimulusresponse pair appeared. Ss were instructed to say aloud the stimulus-response pair during the study interval which lasted $2 \mathrm{sec}$. Ss had been instructed that, once an item was tested, it should be forgotten, since it would never be tested again.

\section{Resulis}

The number of trials intervening between study and test for a given item will be referred to as the lag for that item. Figure 1 presents the proportion of correct responses as a function of lag, averaged over all sessions and Ss. Note that curves have not reached chance performance $(1 / 26)$ by a lag of 13 .

The lower panel of Fig. 2 presents the mean lag judgments as a function of the actual lag for the tested stimulus. The upper panel of the same figure shows the lag judgments conditionalized upon the paired-associate response. We can see that, if an $\mathrm{S}$ makes the correct 
paired-associated response, he is fairly accurate in his judgments of recency up to a lag of 5 , although slightly overestimating the shorter lags. On trials where his paired-associate response is incorrect, the lag judgments are relatively constant about a mean of 5.47, although a slight, but statistically reliable, upward trend over lags does occur.

\section{Discussion}

The results of the present study suggest that an S's information about recency is related to his information about the particular stimulus-response pairing involved. When Ss give incorrect responses to a stimulus, they also tend to give erroneous estimates of the number of intervening items. Up to a lag of 5 or 6 , correct responses are highly correlated with correct recency judgments and, as the proportion of corr act responses decreases toward the guessing level, the recency judgments decrease in accuracy and tend to approach those given for incorrect responses.

Several features of this relationship should be noted. First, since the two conditional curves of Fig. 2 come together before the proportion of correct responses has reached the guessing level, it is suggested that recency information decays at a faster rate than information about correct responses. Second, the fact that the curve conditional upon errors rises over lags suggests that there is some information about recency even when there is insufficient information on which to make a correct response to the stimulus.

There is one final point of interest in the lag judgment data. It appears that when Ss have little or no information on which to make a judgment, they guess a lag with

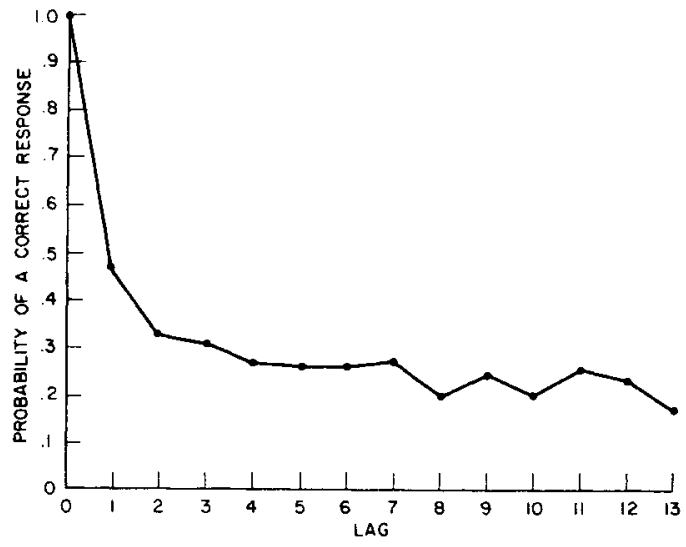

Fig. 1. Probability of a correct response as a function of the Iag between study and test on a given stimulus.

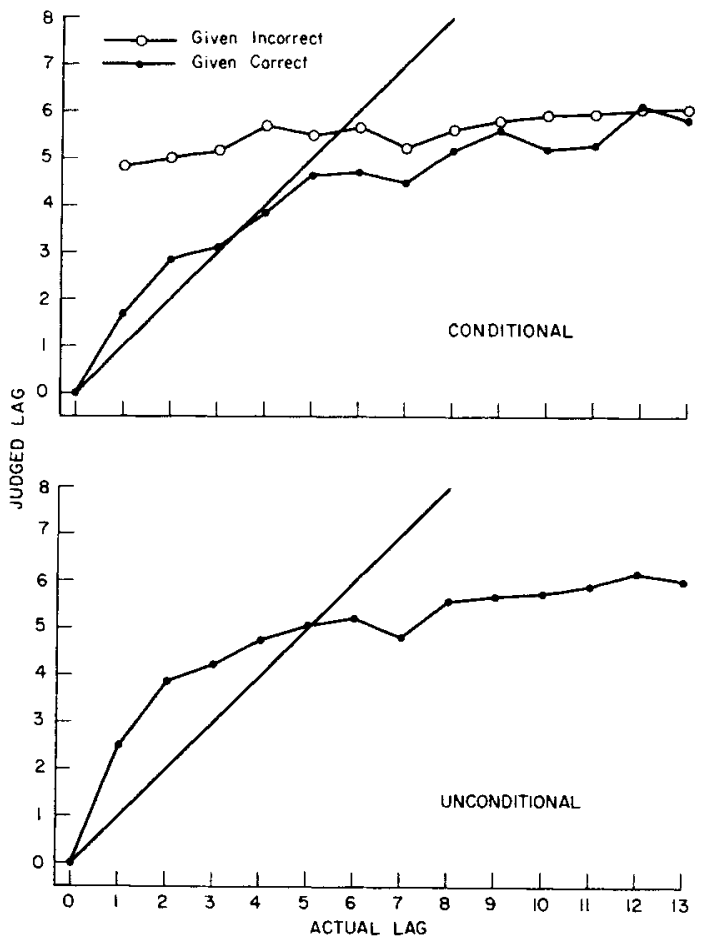

Fig. 2. Mean judged lag as a function of the actual lag, averaged over all Ss and sessions. The diagonal lines represent perfect recency judgments.

a mean of about 5.5. We suggest two possible explanations for this value. It is very close to the mean (or expected) number of lags that occurred in our experiment. The mean lag was approximately 7. Second, 5.5 is near the middle of the set of response keys on which Ss made most of their recency judgments. When Ss have little information on which to make a recency judgment, it might be expected that the optimal strategy would be to guess some value near the mean (either numerically or physically) of all possible lags.

\section{References}

Atkinson, R. C., Brelsford, J, W, \& Shiffrin, R. M. Multi-process models for memory with applications to a continuous presentation task. J. math. Psychol., 1967, in press.

Peterson, L. R. Search and judgment in memory. Paper read at Symposium on Cognition, Carnegie Institute of Technology, 1966.

Yntema, D. B., \& Trask, F. P. Recall as a search process. $J$. verbal Learn. verbal Behav., 1963, 2, 65-74.

Note

1. This study was supported in part by the National Aeronautics and Space Administration, Grant No. NGR-05-020-036. 